\title{
Springer
}

Milan

Berlin

Heidelberg

New York

Barcelona

Hong Kong

London

Paris

Singapore

Tokyo 
Giancarlo Spezie

Giuseppe M.R. Manzella

(Eds)

\section{Oceanography of the Ross Sea Antarctica}

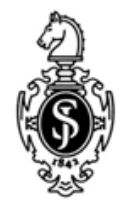

Springer 


\author{
GIANCARLo SPEZIE \\ IUN \\ Institute of Meteorology and Oceanography \\ Via Amm. Acton, 38 \\ 80133 Napoli \\ Italy
}

GiUSEPPE M.R. MANZELLA

ENEA

Marine Environment Research Centre

Loc. Pozzuolo, Forte S. Teresa

19036 S. Terenzo (La Spezia)

Italy

(C) Springer-Verlag Italia, Milano 1999

Softcover reprint of the hardcover 1st edition 1999

ISBN 978-88-470-2252-2

ISBN 978-88-470-2250-8 (eBook)

DOI 10.1007/978-88-470-2250-8

Library of Congress Cataloging-in-Publication Data: applied for

This work is subject to copyright. All rights are reserved, whether the whole or part of the material is concerned, specifically the rights of translation, reprinting, re-use of illustrations, recitation, broadcasting, reproduction on microfilms or in other ways, and storage in data banks. Duplication of this publication or parts thereof is only permitted under the provisions of the Italian Copyright Law in its current version, and permission for use must always be obtained from Springer-Verlag. Violations are liable for prosecution under the Italian Copyright Law.

The use of registered names, trademarks, etc. in this publication does not imply, even in the absence of a specific statement, that such names are exempt from the relevant protective laws and regulations and therefore free for general use.

Typesetting: Photo Life (Milan)

Cover design: Simona Colombo 
To Viviana and Lodovico 


\section{Preface}

The era of the exploration of the World Ocean is not yet over: some areas still lack an adequate number of observations. The relationships between the physical, chemical and biological processes, which sustain the life on this planet, are not yet fully understood. In short, knowledge of the oceans is still far from satisfactory. This book covers an important period in the study of one of the last investigated areas of the World Ocean: the Ross Sea, Antarctica. During the 1990s, long-term experiments were conducted in this area as part of the Climatic Long-term Interaction for the Mass balance in Antarctica (CLIMA) project of the Italian National Programme for Antarctic Research (PNRA), providing a wealth of oceanographic information. This book is an outcome of the CLIMA field observations and international collaborations with the most important programmes in the Ross Sea-Southern Ocean area. It contributes to the studies of the spatial and temporal variability of Ross Sea water masses and circulation and their relationship with the Southern Ocean circulation. A comprehensive review of historical data is offered, and new data sets are analysed.

The studies presented in this book show that much progress has been achieved during the last decade, but large gaps in our understanding of the physical processes in the Ross Sea are still to be filled. However, these studies contribute significantly to the investigation of some specific aspects regarding the circulation of the main water masses.

One of the main aspects of the dynamics of the Ross Sea is the considerable variability over small distance. This poses serious constraints, not easily satisfied, on sampling criteria for hydrological and current measurements. Furthermore, the available CTD (Conductivity Temperature Depth) data are mainly collected during the austral summer, owing to practical reasons. This, along with the uneven sampling distribution, obviously makes the use of in situ data for the initialisation and validation of circulation models aimed at simulating and understanding dynamic processes in the area a particularly delicate issue.

The existing data sets also display a marked seasonal and interannual variability, which is typical of limited areas where distinctive water formation and transformation are occurring. The studies reported in this book show that the Ross Sea has a complex circulation at all depths driven by a combination of factors operating on different, but critically related, time scales. Thus, climatological averages may not be a significant means of characterising the circulation when the investigation is focused on particular aspects of it. Also considered in this book are the relationships between the circulation around Antarctica and in the 
Ross Sea, which develop by dynamic coupling between the Antarctic Circumpolar Current and the Ross Sea Gyre as well as by fluid exchange between offshore larger-scale circulation and local ones. Research on the horizontal and vertical particle flux has increased our knowledge of the intensity of the horizontal and vertical transport of biogenic elements from suspended particulate matter. The data will surely prove very valuable also in the design and implementation of ecological models.

The International Conference on the Oceanography of the Ross Sea held in Lerici, Italy, in March 1997 has constituted the first occasion on which data, model results, and ideas sprung from the activities carried out in the framework of the CLIMA project were presented and discussed in an organic manner. The state of the knowledge achieved within the project is demonstrated by the contributions in this volume, along with the extent of the collaborations which flourished between the project itself, or individual activities conducted in its framework, and major international scientific initiatives. Just to mention a few examples, repeated expendable bathythermograph (XBT) deployments along the World Ocean Circulation Experiment (WOCE) P14 transect between New Zealand and Antarctica have been carried out in the framework of the WOCE; the CLIMA project is also an official contributor to WOCE activities, with the surface drifter data gathered in the Pacific sector of the Antarctic Circumpolar Current, and these data are available to the scientific community through the WOCE-TOGA Global Drifter Data Center located in and hosted by the National Oceanic and Atmospheric Administration (NOAA) in Miami; they also constitute part of the Italian contribution to the WCRP International Programme for Antarctic Buoys (IPAB). Particular attention, in this respect, has been devoted to making data collected within CLIMA activities available to the community at large, again through bilateral collaborations or international data centers.

As mentioned above, this has been the first opportunity to summarise the achieved results, and the stage of the synthesis has not been reached yet, i.e., the point when scientists from the different disciplines can consider the entire set of data and plan its use for the implementation of predictive models of polynya formation, interannual variability of the circulation, and links between physics, chemistry and biology within the Ross Sea ecosystem.

It is also necessary to underline a very crucial point which clearly results from the data analysis: the Ross Sea appears to be a quite complex system, whose continuous and exhaustive monitoring is not feasible, obviously. In the best case, we can expect to be able to carry out measurement campaigns for 2 or maybe 3 months a year. We therefore have to optimise men and equipment resources in order to take advantage of the short "fair weather" (so to speak) time we have for our observations. At the same time, we also need to make the best out of the long months we cannot be in the field. Remotely sensed data collection will fill the gap between campaigns, and therefore we will have to give impulse to the connected analysis and research. Also, we need to keep developing strong numerical modelling activities, at different levels of complexity, with the final goal of covering as much of the complexity of the Ross Sea system as possible.

It has clearly been shown that the Ross Sea can be a good reference site to monitor possible climatic trends, looking at the variability of water mass formation as 
an indicator of global warming. To this end there is the need to pool together the different data sets available and at the same time it is crucial to acquire time series of the Ross Sea characteristics long enough to be able to estimate its contribution to the Southern Ocean system as a whole.

The International Conference on the Oceanography of the Ross Sea developed a number of topics laid out in seven work sessions. We started with a general description and discussion of the physical oceanography of the Southern Ocean and of its most important dynamic feature, the Antarctic Circumpolar Current. Then, we zoomed in and looked at the Ross Sea, the focus of the interest of most of us, in terms of its hydrological as well as its biogeochemical characteristics, and of its circulation. We finished with a session on remote sensing, which is a way to reconnect local analysis to the big picture of the circulation, and, more generally of the overall climatic conditions of the Southern Ocean, of its Pacific sector, and, in particular, once again, of our area of interest: the Ross Sea.

The work discussed over 5 days has involved, and is still involving, more than 120 researchers, and has provided a quite exhaustive picture of the oceanography of the Ross Sea. At the same time, presentations, discussions and round tables have made us aware of a number of still open questions, whose answers will provide a more complete understanding of how the Ross Sea works as a dynamic and ecological system. Also, in this sense, we believe we can view the conference as a success, since it has provided us with some issues which will be our research challenges for the future. 


\section{Contents}

Preface

\section{General Aspects}

Thermohaline Data and Ocean Circulation on the Ross Sea

Continental Shelf

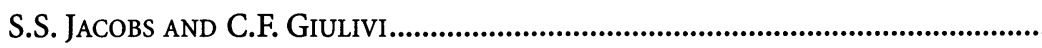

Mapping the Thickness of Pancake Ice Using Ocean Wave Dispersion in SAR Imagery

P. WADHAMs, F. PARMiggiani, G. DE CARolis AND M. TAdross

\section{The Southern Ocean and the Antarctic Circumpolar Current}

Observations of the Dynamics of the Antarctic Circumpolar Current in the Pacific Sector of the Southern Ocean

E. ZAMBIANCHI, G. Budillon, P. FALCO AND G. SPEZIE.

Altimeter Data Analysis of the Antarctic Circumpolar Current

A. Simone, S. ZofFoli, D. IUdicone, R. SANTOlERI AND S. MARUllo

Upper Ocean Thermal Structure and Fronts Between New Zealand and the Ross Sea (Austral Summer 1994-1995 and 1995-1996)

A. Russo, A. Artegiani, G. Budillon, E. Paschini and G. Spezie

The Large-Scale Thermohaline Structure of the Ross Gyre

V. GOURETSKI

Water Masses and Dynamics of the Ross Sea Continental Shelf

Temporal Variability of Currents in the Ross Sea (Antarctica)

P. PicCo, L. AMici, R. Meloni, L. LANGone AND M. RaVAioli

Reconstructing the General Circulation of the Ross Sea (Antarctica)

Using a Robust Diagnostic Model

A. Bergamasco, S. CARNiel AND L. CAlDESI VAleri 
A Wind and Boundary Driven Circulation Model of the Ross Sea

V. COMMOdARI AND S. PIERINI.

Wintertime Expansion and Contraction of the Terra Nova Bay

Polynya

M.L. VAN WOERT

Current, Temperature and Salinity Observations in the Terra Nova Bay Polynya Area

G.M.R. Manzella, R. Meloni ANd P. Picco

\section{Particle Fluxes and Organic Matter}

Particle Fluxes at the Edge of the Ross Ice Shelf: The Role of Physical Forcing

A. Accornero, A. Bergamasco, A. Monaco and S. Tucci

Actual Sedimentation on the Antarctic Continental Shelf (Southern Part of the Ross Sea)

S. TuCCI, M. FerRari AND M. CAPELlo

Particle Fluxes and Sediment Characteristics at Three Selected Sites in the Ross Sea (Antarctica)

M. Ravaioli, M. Frignani, M.C. Gambi, L. LabbrozZi and L. LaNGONE

General Characteristics of Density-Turbidity Currents in the Ross Sea (Antarctica)

S. GREMES CORDERo AND E. SALUSTI

Vertical Distribution and Biochemical Composition of Pico- and Microparticulate Organic Matter in the Ross Sea (Antarctica)

M. FABIANO, R. DANOVARO AND P. POVERO

\section{Meteorological Processes}

On the Heat Energy Fluxes in the Non-stationary Surface Boundary

Layer at Hells Gate, Terra Nova Bay (Antarctica)

S. Ferrarese, C. Cassardo, A. Longhetto, D. Bertoni, R. Forza,

G. Ficca, M. PANGia ANd R. PURINI.

Meteorological Conditions During Snowfall at Terra Nova Bay (Antarctica)

A. Pellegrini, A.M. Della Vedova, P. Grigioni and L. De Silvestri 